Article

\title{
Consumers Preferences for Dairy-Alternative Beverage Using Home-Scan Data in Catalonia
}

\author{
Mohamed Laassal ${ }^{1}$ and Zein Kallas ${ }^{2, * \mathbb{D}}$ \\ 1 National Office of Food Safety (ONSSA), Rabat 10000, Morocco \\ 2 Centre for Agro-food Economy and Development (CREDA-UPC-IRTA), Casteldefells 08860, Spain \\ * Correspondence: zein.kallas@upc.edu; Tel.: +34-935521213
}

Received: 24 May 2019; Accepted: 5 August 2019; Published: 2 September 2019

\begin{abstract}
The changing lifestyles and the growing health concerns towards the negative impact of the saturated fatty acids originating from animals has increased consumers' preferences for dairy-alternative products. These products belong to the food and beverage classification that is similar to certain types of dairy-based products in terms of texture and flavor, and has similar nutritional benefits. In this context, we seek to identify the willingness to pay (WTP) for the most important attributes that consumers take into account when purchasing the dairy-alternative drinks. A revealed preference discrete choice experiment was carried out using home-scan data belonging to (C)Kantar Worldpanel (Barcelona, Spain) regarding the consumption of dairy-alternative drinks in Catalonia (Spain) in 343 households. Furthermore, factors that affect the purchasing frequency of this type of product were analyzed through the Poisson and negative binomial models. Results showed that price was the major driving factor, followed by the original non-dairy beverage flavor attribute. The original non-dairy beverage flavor compared to other added ingredients and tastes showed higher WTP when purchasing the non-dairy alternative. Marketing strategies should promote products by focusing on the "original" and "pure" version of the product without additional ingredients, or through reduction of the undesirable compounds if they exist in these kinds of beverages.
\end{abstract}

Keywords: dairy alternatives drinks; consumers' preferences; home-scan data; revealed discrete choice experiment; purchase frequency

\section{Introduction}

Growing health awareness, the rising preferences for vegan diets, and the presence of frequent cases of lactose intolerance within the European population [1] have increased consumers' preferences for dairy-alternative products. Amongst the main factors that are driving the growth of this sector, changing lifestyles and the growing health concerns towards the negative impact of the saturated fatty acids originating from animals are among the most driving factors. By consuming the vegetable milk-substitute formulations, particularly soy milk, some of the potentially deleterious aspects of animal products, such as the cholesterol, can be avoided [2]. Moreover, the increasing prevalence of cases of cow's milk protein allergies [3] is another driving factor affecting the adoption of these types of beverages.

The dairy-alternative sector is mainly segmented on the basis of "type" into soy milk, oat milk, rice milk, almond milk, and others. According to the Spanish regulation, the word milk cannot be used to refer to these beverages with the exception of almond. However, it is widely known amongst consumers as vegetable milk. These products are also segmented on the basis of "formulation characteristic" into plain-sweetened, plain unsweetened, flavored sweetened, flavored-unsweetened, and others, along with several "flavor" and "format" descriptors within the food and beverages class. According to the Europe Dairy Alternative Market [4], the market of those products in Europe 
constitutes $21.2 \%$ of the global market and was valued at $€ 1797.38$ million in 2013 , reaching $€ 2765.54$ million by 2018 . The main dairy alternatives in the EU are soy milk $(70.5 \%)$, almond milk $(14.64 \%)$, rice milk $(7.9 \%)$, and others $(6.8 \%)$. The market has increasingly benefited in recent years from the perceived health and taste benefits of dairy-alternative products. Soy milk, and soy products in general, are rich in isoflavones which have attracted the consumer's interest as potential health-promoting foods [5]. Spain reached the highest percentage amongst France, Germany, Italy, Poland, and the UK in its consumption [6]. About 15\% of European consumers avoid dairy products for a variety of reasons, including medical reasons such as lactose intolerance (LI), cow's milk allergy (CMA), cholesterol issues, and phenylketonuria, as well as lifestyle choices like a vegetarian/vegan diet or concerns about growth hormones or antibiotic residues in cow's milk $[7,8]$.

It is expected that this sector will continue to grow, which makes the analysis of consumers' preference analysis of these products highly relevant in order to propose reliable patterns and suggest recommendations that may allow marketers to better target the different market segments and to improve the profitability in the dairy-alternative drinks industry. According to Oltenacu and Broom [9], the increased production in dairy cattle should be viewed with concern because the increase in milk yield has been accompanied by a decline in cows' welfare including fertility problems, increasing leg and metabolic diseases, decreased longevity, higher disease incidence, and modification of normal behavior. Improving animal welfare is important as it is regarded by the public as indicative of sustainable systems and good product quality. Decreasing the intensity of the intensive milk production farming would contribute to more sustainable consumption patterns. Therefore, taking into account the resource availability and the consequences of functioning and morality of action [10], we will consider animal welfare as one of the relevant factors that contribute to more sustainable production systems [11].

In this context, the objective of this paper is twofold. Firstly, to analyze consumers' preferences toward dairy-alternative products in Catalonia. In particular, to identify the willingness to pay (WTP) for the most important attributes that consumers take into consideration when purchasing dairy-alternative drinks. Secondly, to study the determinant factors that affect the purchasing frequency of the dairy-alternative products.

To achieve the abovementioned objectives, we carried out a revealed discrete choice experiment analysis by estimating mixed logit model in the WTP space in order to better understand the consumers of dairy-alternative drinks and the actual trends driving their purchasing behavior. We also performed a Poisson regression and a negative binomial model using the purchase frequency variable as the revealed count data. Data were collected from the home-scan data belonging to (C) Kantar Worldpanel, (Barcelona, Spain), which included a representative sample of Catalan households that scanned and transmitted their store-bought food and beverage purchases on a daily basis by using the bar codes and a reading device at home during the year.

\section{Materials and Methods}

The application of the discrete choice experiment (DCE) involves the characterization of a product through a series of attributes and their levels that can be combined, following an experimental design, to create different scenarios of the product. These scenarios are presented in an array of "choice sets" representing different possible "states" of the product. Subjects are asked in a survey to select their preferred "product" within each choice set or neither of them. This approach allows us to understand the trade-offs that participants are willing to make among the descriptors of the product, thereby revealing their preference for certain characteristics. The DCE can be hypothetical (hypothetical discrete choice experiment, H-DCE) by asking consumers to select their preferred product by only simulating their behavior in a real market place. This approach may suffer from the hypothetical bias, induced by the hypothetical nature of surveys. This bias is defined as the difference between what a respondent indicates he/she would purchase in a survey or interview and what he/she would actually do in the real market. According to Loomis [12], hypothetical bias in surveys reflects the old saying that "there is a difference between saying and doing". In this context, hypothetical surveys are, in 
general, not incentive compatible. That is to say, its dominant strategy would not truthfully reveal the real value that the product has to the consumer. Loomis [12] summarized an array of different ex-ante and ex-post approaches to reduce the hypothetical bias in surveys. One of the ex-ante ways is to let the survey to be consequential to the respondent. This approach constitutes the basic form of the non-hypothetical discrete choice experiment (NH-DCE) by creating a "real shopping scenario" at the end of the survey $[13,14]$. Individuals who agree to participate are asked to purchase their preferred product from a randomly selected choice set and to mandatorily pay its posted price. In the NH-DCE, participants are, in general, rewarded by real money that at least covers the highest price level of the products presented in the choice sets. Both approaches (i.e., the H-DCE and NH-DCE) belong to the stated preference method, where consumers "state" in a survey their preferences.

Opposite to the stated preference approach, consumers' preferences can be elicited using revealed preference data. In this case, the observation of the purchasing behavior "reveals" what they prefer. The revealed preferences can be carried out by means of scanner data, which are electronic records of transactions that the establishments collect as part of the operation of their businesses, most commonly collected via the scanning of the bar codes at checkout lines of retail stores [15]. Hence, scanner information constitutes a nontraditional data source for economic application [16]. Scanner data collected on consumer purchases come from two types of sources: Point-of-sale (retail) or store scanner data sources, which use the universal product code (UPC) of products sold at retail checkout counters to identify products and quantities sold and their prices; and household-based scanner data, which are derived from a sample of households that scan universal product codes (UPCs) of all purchased products after each shopping trip. In this case, even though the entire panel scans all products with a UPC, a subset of the panel also records purchases of random-weight or non-UPC products from other stores than the usual supermarkets (e.g., butchery, corner stores, self-services, greengrocers, bakeries, and others); households scan them through special codes provided by the owner of the data sets in order to collect and record all the possible food and beverage acquisitions. Although point-of-sale scanner data have been available to academic researchers since at least the early 1980s, household-based scanner data are a more recent innovation.

The scanner type of data can be integrated to the stated choice experiment data, as was done in the seminal work of Adamowicz et al. [17] and others [18-21] that combined the revealed and stated preference. Models' estimates based on pooled data may reduce the hypothetical bias and improve the goodness of fit of the models in preference analysis and predictions. In addition, scanner data have been used in several economic studies for decades to answer a variety of questions about food consumption, food pricing, and the operation of retail food markets. Most applications have used retail data and only a few have used household data or a combination of the two. Scanner data have been used most often to examine pricing behavior in particular product markets, including the influence of private label foods on name brand pricing [22], strategic pricing responses in markets [23], and the effect of political pressure on prices [24]. Scanner data have also been used to measure the value of product attributes [25] and to analyze seasonality in prices and consumption [26]. Scanner data have been used for policy-relevant food and nutrition research, such as studying the effects of mandatory nutrition labeling [27], among other research.

Our study fit within the preference analysis carried out exclusively on the revealed choice data, similar to the applications of Guadagni and Little [28], Pancras and Dey [29], and Wasi and Keane [30], among others. Guadagni and Little [28] carried out a multinomial logit choice model calibrated on scanner data on coffee purchases, which computed the probability of choosing an alternative as a function of the attributes of all the alternatives available. This study permitted an explicit assessment of several explanatory variables, namely; brand loyalty, size loyalty, presence/absence of store promotion, regular shelf price, and promotional price cut. Although, it received some criticism due to factors such as the missing modeling of the purchase occasion and the fact that the coefficients of these variables were modeled to be the same for all coffee brand sizes. Pancras and Dey [29] applied discrete choice modelling using the latent class and the generalized multinomial logit models on the AC Nielsen 
scanner panel data in the United States on the ketchup category from the largest retailer market. Wasi and Keane [30] applied discrete choice modelling on frozen pizza choice using retailer-scan data by selecting random subsets of the full choice of 100 varieties of pizza in order to construct their choice set. In this context, consumers' purchasing behavior from scan data allowed them to estimate consumers' preferences and willingness to pay.

Home-scan data are individual detailed data on sales of consumer goods obtained by 'scanning' the bar codes for individual products using an electronic device within households. The availability in academic research of this data type is scarce because of its high cost. However, it is worth the effort because this kind of information is very timely and precise, which may allow researchers to accurately analyze preferences in a revealed context approach. In fact, during the past two decades, the studies using revealed data sets have increased considerably and become more prevalent as they provide huge opportunities for consumers' preference research and marketing decision making on one hand, and a managerial tool for retailers on the other [16]. This type of data collection has remarkable advantages over traditional data collection by avoiding so many hypothetical and strategic biases of questionnaires. Also, it offers opportunities to improve the stated techniques to analyze consumer preferences by allowing research to investigate the gap between what people do in real life and what they say to do in surveys. It deals with the conflict of goals in reaching both the representativeness and the continuity of the observed items [31]. Adding to that, this data type allows us to observe individual household decisions continuously by identifying their economic and sociodemographic characteristics [32]. The simultaneous collection of data regarding price, quantity purchased, and the frequency of purchase is another substantial advantage over conventional cross section data.

The main issues with the use of home-scan data sets are related to the credibility and validity of the information reported, because they are self-recorded and the recording process is time-consuming [33]. Households who agree to participate in the sample might not be representative of the observed population, since the acceptance to participate is not fully random and is, in general, unbalanced in regards to technology education. Furthermore, household who agree to participate may not record their purchases accurately or may misreport some trip information about the store and date [33]. According to Hardesty et al. [34], the scanner data collection may suffer from bias related to the discrepancies between the shelf label price and the scanning system's charge. These inaccuracies in scanned prices may have relevant implications on marketing models and the interpretation of results. Furthermore, the household scanning panels are slightly more price-sensitive [35]. Another issue is related to who participates in home-scan data. According to Lusk and Brooks [35], the home-scan data may suffer from sample selection and participation biases. The preferences analysis based on home-scan data also omits the position of the product on store shelves. The shelf positioning of products at retail places plays an important role in affecting the purchase decision [36]. Accordingly, results based on home-scan data should be treated with care taking into account the potential sources of bias.

\subsection{Data Base}

The data collection used in this study followed the ethical principles according to the Spanish and European regulations on protecting personal information and ensuring anonymity. Households included in this database signed a consent form and received an explanation about how they should collect the data. Participants were economically compensated for their participation. A data set including only the purchase of dairy-alternative drinks was separated from the original data set that included many product categories, e.g., oil, olives, meat, dried fruits, fruits and vegetables, eggs, honey, bread, etc., in order to fulfill the research objectives.

These data have been extracted from an even bigger fixed sample of households, representative of the population of Spanish households, which allows for continuously analyzing and studying the acts of purchase. The company's network in Spain consists of households selected by stratification according to several socioeconomic variables. Proportional both demographically and by region, recruitment, selection, and maintenance ensure quality control of the data are guaranteed due to 1935 
polling points and 12,000 cooperating households equipped with a barcode reader each, transmitting complete information about food purchases. Even though the entire panel scans all products with the electronic device, a subset of the panel also records the purchases of random-weight (i.e., with no bar code) from other stores than the usual supermarkets (e.g., butchery, corner stores, self-services, greengrocers, bakeries and others). In this case, households scan products through special codes provided by the company, Kantar (Barcelona, Spain), in order to collect and record all the possible food and beverage acquisitions into the data set. The resulting data set representing all the dairy-alternative products purchased by households within the sample during one year resulted in 5746 observations. The panel provides rich information about every single act of purchase as if it was recreated. In other words, detailed data about each of the families, the product purchased, its attributes, and the circumstances of the act of purchase are collected. It is worth highlighting that personal data (names, address, e-mail, or phone) were not recorded.

\subsection{Consumers' Preferences Analysis Approach}

Consumers' preferences and the willingness to pay were analyzed following the discrete choice experiment (DCE). The DCE is one of the most used methods because of its capacity to analyze complex goods such as food and beverages products and because of its ability to analyze the WTP and the marginal utility of a product's attributes and levels. The DCE is derived from the consumer theory of Lancaster [37] and the random utility theory. The former postulated that the utility of a product is obtained from the characteristics that the good possesses, rather than the good per se. The latter suggests that subject $n$ chooses product $j$ from a set of alternative products $(T)$ according to a utility function $U_{j n}$ with a systematic component $V_{j n}$, a vector of $\mathrm{k}$ attributes, a random error term $\varepsilon_{j n}$, and socioeconomic characteristics of individual $S_{n}$.

$$
U_{j n}=V_{j n}\left(X_{j}, S_{n}\right)+\varepsilon_{j n} .
$$

Different discrete choice modeling approaches are available to predict the probability of individuals choosing one product from the choice set $(t)$ of products. The different approaches are obtained from different specifications of the different assumptions about the distribution of the error term [38]. The multinomial logit (MNL) developed by McFadden [39] is one of the basic models. However, the MNL imposes homogeneity of preferences for observed attributes. Thus the mixed or heterogeneous logit models (known also as random parameter logit, RPL) were introduced to handle this restriction $[40,41]$.

The RPL model extends the MNL, introducing the unobserved heterogeneity by allowing random coefficients of attributes [42]. In this case, the utility to person $n$ from choosing alternative $j$ on purchase occasion (or in choice set $t$ ) is given by:

$$
U_{n j t}=\left(\beta+\eta_{n}\right) x_{n j t}+\varepsilon_{n j t} \quad n=1, \ldots, N j=1, \ldots, J t=1, \ldots, T
$$

Here, $\beta$ is the vector of mean attribute utility weights in the population, whereas $\eta_{n}$ is the vector of person n-specific deviations from the mean. The idiosyncratic error $\varepsilon_{n j t}$ is assumed to be an independent and identically distributed (i.i.d.) extreme value and has a variance that has been implicitly normalized (to that of the standard extreme value distribution) to achieve identification. The researcher may specify any distribution for the $\eta_{n}$ vector, but in most applications it is assumed to be multivariate normal [43].

Regardless of the different models used to analyze choice data for interpretation, the marginal rate of substitution (MRS) between attributes can be calculated. Once parameters are estimated and one of the attributes is expressed in monetary terms (i.e., the price), it is possible to determine the willingness to pay (WTP) for each level of the attributes by calculating the negative quotient of the coefficient of any nonmonetary attribute by the coefficient of the price. 


$$
W T P_{\text {Product_attribute }}=-\left(\frac{\beta_{\text {Product_attribute }}}{\beta_{\text {monetary_attribute }}}\right)
$$

According to Hole and Kolstad [44], the RPL makes it possible to account for heterogeneity in preferences which are unrelated to observed characteristics, and it has been shown that any discrete choice random utility model can be approximated by an appropriately specified RPL. When estimating the RPL, the researcher specifies that the distribution of preferences follow a particular distribution, for instance a normal distribution. The parameters of this distribution, such as the mean and the standard deviation in the case of a normal distribution, are then estimated.

Since the WTP for an attribute is given by the ratio of the attribute coefficient to the monetary coefficient, the WTP from a RPL model is given by the ratio of two randomly distributed terms, if the monetary term enters in the model as random. Depending on the choice of distributions for the coefficients, this can lead to WTP distributions that are heavily skewed and that may not even have defined moments. A common approach to dealing with this potential problem is to specify the monetary coefficient to be fixed (i.e., nonrandom). This is a convenient assumption, as in this case the distribution of the willingness to pay for an attribute is simply the distribution of the attribute coefficient scaled by the fixed price coefficient. The problem is that it is often unreasonable to assume that all individuals have the same marginal utility of income, so this approach implies an undesirable trade-off between reality and modeling convenience [44].

Train and Weeks [45] suggest another solution to circumvent this problem by estimation of the RPL in WTP space, rather than in preference space (i.e., the above-described approach). This involves estimating the distribution of willingness to pay directly by reformulating the model in such a way that the coefficients represent the WTP measures. The researcher then makes priori assumptions about the distributions of WTP rather than the attribute coefficients. According to the RPL in the WTP space model, the utility person (decision makers) $n$ derives from choosing product $j$ in choice situation $t$ is specified as a function of the price $\left(p_{n j t}\right)$ and other nonmonetary attributes of the product $\left(x_{n j t}\right)$. That is specified as separable in price and nonprice attributes to facilitate discussion:

$$
U_{n j t}=-\alpha_{n} p_{n j t}+\beta_{n}^{\prime} x_{n j t}+\varepsilon_{n j t}
$$

where $\alpha_{n}$ and $\beta_{n}$ are individual specific coefficients for the price and the other attributes of the product and vary randomly across decision makers (consumers) and $\varepsilon_{n j t}$ is extreme value distribution, though the analysis is analogous to other distributions. Since the WTP for an attribute is the ratio of the attribute's coefficient to the price coefficient, the utility can be rewritten as:

$$
U_{n j t}=-\lambda_{n} p_{n j t}+\left(\lambda_{n} w_{n}\right)^{\prime} x_{n j t}+\varepsilon_{n j t}
$$

which is what Train and Weeks [45] call the model in WTP space. Under this parameterization, the estimated coefficients are directly considered as the WTP values. The WTP space model has been applied in a several studies, in particular within the disciplines of environmental economics and marketing. These models were found to produce more realistic WTP measures [44].

\subsection{Factors Affecting the Purchase Frequency}

The determinant factors that affect the frequency of purchasing of dairy-alternative products were analyzed. This section specifies the model that was used to study the variables that affect the frequency of purchasing dairy-alternative products. Specifically, the dependent variable measured how many times individuals have purchased dairy-alternative products by month during one year. This variable is count data and can only take non-negative integer values. In this context, the ordinary least squares (OLS) estimation can generate biased, inconsistent, and inefficient estimates [46]. Thus, count data models are a better alternative. 
Count data models (Poisson and negative binomial) are nonlinear regression models for counts estimated by maximum likelihood. The standard model for count data is the Poisson model. The Poisson model is a nonlinear regression model based on the Poisson distribution [47].

For a discrete random variable observed over a period of length $T$, and observed frequencies, $y_{i}, i=1, \ldots, n$, where $y_{i}$ is a non-negative integer count, which represent the number of occurrences of the event of interest by the $i_{t h}$ customer. Assume that $y_{i}$ is distributed according to a Poisson distribution:

$$
\operatorname{Pr}\left(y_{i} \mid \lambda_{i}, T\right)=\frac{\exp \left(-\lambda_{i} T\right)\left(\lambda_{i} T\right)^{y_{i}}}{y_{i} !}
$$

where $\lambda_{i}=E\left(y_{i}\right) / T$ is the purchase frequency. Covariates can be introduced into this model by relating them to the purchase frequency through a $\log$ linear model: $\lambda_{i}=\exp \left(x_{i}^{\prime} \beta\right)$, where $x_{i}$ denotes the vector of the $i_{t h}$ subject's characteristic variables and $\beta$ is the corresponding coefficient vector of $x_{i}[48]$.

The standard application of the Poisson model is constrained by its equidispersion assumption, which considers equality for the conditional mean and variance of the dependent variable (i.e., purchase frequency). In practice, the variance of the data is often greater than the mean, resulting in inconsistent estimates of model parameters when the Poisson likelihood is used [48]. In all cases, overdispersion has little effect on parameter estimates but leads to underestimation of standard errors [49]. To accommodate this overdispersion, one can assume a random-effects distribution for $\lambda_{i}$ instead of a $\log$ linear model. This assumption results in a model capable of reflecting data with greater variation. When the random effects are assumed to be gamma distributed, the result is the negative binomial distribution (NBD) model, which adds a parameter to the P model that reflects unobserved heterogeneity and overcomes the problem of overdispersion. Accordingly, the probabilities in the negative binomial model are given by:

$$
\operatorname{Pr}\left(Y=y_{i} \mid x_{i}\right)=\frac{\theta^{\theta} \lambda_{i} y_{i} \Gamma\left(y_{i}+\theta\right)}{\Gamma(\theta) y_{i} !\left(\lambda_{i}+\theta\right)^{y_{i}+\theta}}
$$

where $\theta$ is the over dispersion parameter. The connection between the two models is that the Poisson model results if $\alpha=1 / \theta=0$ [50].

\subsection{Empirical Application}

\subsubsection{Consumers' Preferences Analysis Approach}

The first step in any empirical application of the DCE is to correctly identify the attributes and levels that constitute the main characteristics of the studied product. As we are using revealed home-scan data, we were able to identify all the attributes and levels that appear in the description of each purchased product in a real situation. Due to the impossibility to cope with all the attributes and levels, we selected an array of the most important ones, focusing on the attributes that we were interested in and that we hypothesized that consumers take into consideration when purchasing dairy-alternative drinks, including the brand label, biological information, type of vegetable drink, flavor, additional ingredients, and price. In a subsequent step, we identified the different levels to consider. The attribute type, flavor, and additional ingredients had a high number of levels, which led to a large number of products or alternatives to be included in the choice sets, with only a few purchases in the whole data set. Therefore, we performed an aggregation procedure of levels of the few purchased products (less than 5\%) and irrelevant levels. Finally, the levels of the "type" attribute were: Soy, oats, rice, and other. For the attribute "biological information", the level was: Organic or not. For the flavor attribute, the levels were: Original non-dairy beverage flavor, chocolate, and other flavors. For the "additional ingredient" attribute, the levels were: Without added ingredient, with added calcium and vitamins, with added natural calcium, and with other added ingredients. As a result, 56 real categories were identified, of which 26 were soy drink, seven were rice drink, 13 were 
oat drink, and 10 were other vegetable type drink. Thus, we considered the 56 existing categories in the data set arranged into only one choice set.

The construction of choice sets using revealed data sets do not follow the traditional choice design (full factorial, fractional, and orthogonal or D-efficient design). In this case, the choice set in the DCE calibrated on the home-scan data would be as the consumer was confronted by a situation when he/she is at a point of purchase aiming to buy non-dairy alternative beverages, faced with several products. The available products on shelves represent a unique choice set where the consumer has to choose his/her preferred product in every purchasing occasion. To construct the choice set, we first determined the number of available products to be included. Two main limitations were identified:

Firstly, the set of the available products is not the same in each supermarket/hypermarket because they have different number of product references (brands and sub-brands) and marketing strategies. This means that the revealed choice set to be constructed will not be the same among the different purchasing points available in the data set. That is, for instance, if a consumer purchased in supermarket $\mathrm{X}$ he/she would face a set of products that is different to the choice set offered in supermarket $\mathrm{Y}$. This limitation was avoided by the aggregation procedure we followed, in which different references (products) were allocated to the same category. For instance, if the product $A$ is only offered by Supermarket $X$ and the product $B$ is only offered in Supermarket $Y$, both products (A and B) will be assigned to the same category because the aggregation procedure was carried out on a common set of the attributes that are the same in all purchasing points.

Secondly, the individual frequency of purchasing the dairy alternatives (i.e., by panelist) was not equal among panelists during the year, which means that the number of choice sets to be constructed will be different for each group of panelists (according to how many time they purchased during the year). For instance, if one consumer purchased only once during the year and only one product by purchase, he/she should only face one constructed choice set. Furthermore, if one consumer purchased twice during the year and only one product by purchase, he/she should face two constructed choice sets and so on. This limitation was easily treated by introducing the nature of the unbalanced panel of the data set into the estimation procedure when estimating the model. In this case, for the price attribute, because of the aggregation of irrelevant levels and attributes, we obtained an array of different categories, in which each one contained more than one real purchased product. As a result, we considered all the aggregated categories in a unique choice set consistent with all the recorded purchases in all the points of purchase.

As a result, we considered all the aggregated categories in a unique choice set consistent with all the recorded purchases in all the points of purchase. For each observation (purchase action), we observed which choice was made and we registered "one" in the choice variable corresponding to the purchased category belonging to the product, and zero otherwise depending on the buying record in every observation in the database. Thus, within each block of 56 rows, the choice variable will be one once and zero otherwise. This structure of the arrangement is the standard way to estimate discrete choice modelling [51].

Regarding the price attribute, because of the aggregation of irrelevant levels and attributes, we obtained an array of different categories, in which each one contained more than one real purchased product. Thus, for the price attribute, we calculated from the individual price of the purchased product a monthly average of all the products that belong to each grouped category. Price was introduced in the modeling estimation as a continuous variable and the rest of attributes were effect-coded. The effect codes use only ones, zeros, and minus ones to convey all of the necessary information, and it allows the interpretation of the estimated coefficient $\beta$ as the difference in marginal utility that the respondent gets with respect to the conditional mean or the average utility of the alternative. 


\subsubsection{Factors Affecting the Purchasing Frequency of Dairy Alternatives}

Different models were used to study the covariates that affect the frequency of purchasing, using the purchase frequency variable as a revealed count data; the dependent variable measured how many times individuals have purchased dairy-alternative drinks by month during one year.

The models estimated were the Poisson regression model $(\mathrm{P})$ and the negative binomial model (NB), and the two models were estimated, respectively, by the packages msm and MASS with the software R [52]. As mentioned, the dependent variable was the purchasing frequency of the dairy alternatives and the independent variables included in the two models comprise expenditure of the shopping basket, expenditure on the dairy-alternative drinks, number of purchased units, life cycle, general study of medias (GSM), class, social class, homemaker's age, metropolitan habitat, municipal habitat, nationality, household members, children presence, province, region, dogs presence, body mass index (BMI), and number of the visited purchase places.

\section{Results and Discussion}

Table 1 summarizes the sociodemographic characteristics of the sample, which consisted of 343 Catalan households.

Table 1. Sociodemographic characteristics of the sample.

\begin{tabular}{|c|c|c|c|}
\hline \multicolumn{2}{|c|}{ Sociodemographic Characteristics } & \multirow{3}{*}{$\begin{array}{c}\text { Percentage } \\
92.42 \% \\
7.58 \%\end{array}$} & \multirow{3}{*}{$\begin{array}{c}\text { Population * } \\
85.76 \% \\
14.24 \%\end{array}$} \\
\hline & Spanish & & \\
\hline Nationality & Others & & \\
\hline \multirow{9}{*}{ Life cycle } & Independent adults & $7.58 \%$ & $8.07 \%$ \\
\hline & Single-parent households & $8.45 \%$ & $6.13 \%$ \\
\hline & Young independent households & $2.92 \%$ & - \\
\hline & Adult couple without children & $16.33 \%$ & $13.11 \%$ \\
\hline & Couples with children of middle age & $16.62 \%$ & - \\
\hline & Couples with older children & $13.70 \%$ & - \\
\hline & Couples with young children & $16.62 \%$ & - \\
\hline & Young couple without children & $6.71 \%$ & $11.10 \%$ \\
\hline & Retirees & $11.08 \%$ & $14.26 \%$ \\
\hline \multirow{4}{*}{ Social class } & Higher + M higher (above 3000€) & $23.03 \%$ & $20.70 \%$ \\
\hline & Middle (2000-3000€) & $39.36 \%$ & $37.40 \%$ \\
\hline & M Lower (1000-2000€) & $22.45 \%$ & $24.20 \%$ \\
\hline & Lower (below 1000€) & $15.16 \%$ & $17.80 \%$ \\
\hline \multirow{4}{*}{ Age of homemaker } & From 18 to 35 & $8.45 \%$ & $16.57 \%$ \\
\hline & From 35 to 49 & $40.23 \%$ & $24.21 \%$ \\
\hline & From 50 to 64 & $37.61 \%$ & $19.70 \%$ \\
\hline & More than 64 & $13.70 \%$ & $18.92 \%$ \\
\hline \multirow{5}{*}{ Household members } & One member & $14.29 \%$ & $10.54 \%$ \\
\hline & Two members & $30.03 \%$ & $25.47 \%$ \\
\hline & Three members & $23.32 \%$ & $24.70 \%$ \\
\hline & Four members & $25.66 \%$ & $26.92 \%$ \\
\hline & Five members or more & $6.71 \%$ & $12.37 \%$ \\
\hline \multirow{3}{*}{ Children presence } & Households with young children & $16.62 \%$ & \multirow{3}{*}{$\begin{array}{l}47.17 \% \\
52.83 \%\end{array}$} \\
\hline & Households with older children & $17.20 \%$ & \\
\hline & Household without children & $66.18 \%$ & \\
\hline \multirow{5}{*}{ Municipal habitat } & Less than 10,000 & $17.49 \%$ & $18.51 \%$ \\
\hline & $10,001-30,000$ & $16.03 \%$ & $17.58 \%$ \\
\hline & $30,001-100,000$ & $21.28 \%$ & $21.16 \%$ \\
\hline & $100,001-500,000$ & $16.91 \%$ & $21.43 \%$ \\
\hline & $500,000+$ & $28.28 \%$ & $21.32 \%$ \\
\hline
\end{tabular}


Table 1. Cont.

\begin{tabular}{|c|c|c|c|}
\hline \multicolumn{2}{|c|}{ Sociodemographic Characteristics } & \multirow{2}{*}{$\begin{array}{c}\text { Percentage } \\
75.51 \%\end{array}$} & \multirow{2}{*}{$\begin{array}{c}\text { Population * } \\
73.86 \%\end{array}$} \\
\hline \multirow{4}{*}{ Province } & Barcelona & & \\
\hline & Gerona & $9.91 \%$ & $9.90 \%$ \\
\hline & Lerida & $6.41 \%$ & $5.67 \%$ \\
\hline & Tarragona & $8.16 \%$ & $10.57 \%$ \\
\hline
\end{tabular}

* Source: Idescat [53].

\subsection{Attribute Preferences of Dairy-Alternative Products}

The results of RPL in the WTP space model are presented in Table 2. The goodness of fit was assessed through a highly acceptable McFadden's pseudo- $R^{2}$. A pseudo- $R^{2}$ of 0.3 represents a decent model fit for a discrete choice model. Values between the range of 0.3 and 0.4 can be translated as an $\mathrm{R}^{2}$ of between 0.6 and 0.8 for the linear model equivalent [51].

Table 2. Estimates for models parameterized in willingness to pay (WTP) space.

\begin{tabular}{|c|c|c|}
\hline Attributes & Levels & Random Parameters $\beta$ s \\
\hline Organic & Yes, $\beta 1$ & $-1.16^{* * *}$ \\
\hline Label & Branded, $\beta 2$ & $0.18^{* * *}$ \\
\hline \multirow{2}{*}{ Flavor } & Original, $\beta 3$ & $0.89^{* * *}$ \\
\hline & Chocolate, $\beta 4$ & $0.11^{* * *}$ \\
\hline \multirow{3}{*}{ Additional ingredients } & Without additional ingredients, $\beta 5$ & $0.27^{* * *}$ \\
\hline & Calcium and vitamins, $\beta 6$ & $0.16^{* * *}$ \\
\hline & Natural calcium, $\beta 7$ & $-0.17^{* * *}$ \\
\hline \multirow{3}{*}{ Type of vegetable } & Soy, $\beta 8$ & $0.56^{* * *}$ \\
\hline & Oats, $\beta 9$ & $0.23^{* * *}$ \\
\hline & Rice, $\beta 10$ & $-0.19^{* * *}$ \\
\hline \multicolumn{2}{|c|}{ Price, $\beta 11$} & 1.0 fixed parameter \\
\hline & & S.D. of random parameters $\beta \mathrm{s}$ \\
\hline Organic & S.D. Yes & $0.89^{* * *}$ \\
\hline Label & S.D. Branded & $0.71^{* * *}$ \\
\hline \multirow{2}{*}{ Flavor } & S.D. Original & $0.04^{* * *}$ \\
\hline & S.D. Chocolate & $0.04^{* * *}$ \\
\hline \multirow{3}{*}{ Additional ingredients } & $\begin{array}{c}\text { S.D. Without additional } \\
\text { ingredients }\end{array}$ & $0.12^{* * *}$ \\
\hline & S.D. Calcium and vitamins & $0.12^{* * *}$ \\
\hline & S.D. Natural calcium & $0.12^{* * *}$ \\
\hline \multirow{3}{*}{ Type of vegetable } & S.D. Soy & $0.06^{* * *}$ \\
\hline & S.D. Oats & $0.33^{* * *}$ \\
\hline & S.D. Rice & 0.008 \\
\hline \multicolumn{2}{|c|}{ Log-Likelihood $(\theta)$} & -9102.62 \\
\hline \multicolumn{2}{|c|}{ Log-Likelihood (0) } & -16045.05 \\
\hline \multicolumn{2}{|c|}{ Pseudo $\mathrm{R}^{2}$} & 0.43 \\
\hline
\end{tabular}

As mentioned before, this modelling approach allows for estimation the distribution of willingness to pay directly by reformulating the model in such a way that the coefficients represent the WTP measures. Then, we made priori assumptions about the distributions of WTP rather than the attribute coefficients. A salient feature of the WTP space model is that the estimated parameters are also 
the parameters of the implied WTP distributions. We estimated models with utility, as specified in Equation (5), where the coefficient of each non-price attribute is the product of the WTP for that attribute times the price coefficient. The price coefficient $-\lambda_{n}$ was given a normal distribution [54] and the elements of $w_{n}$ (i.e., WTPs) were also specified to be normal [45]. The WTPs were assumed to be uncorrelated over attributes. In Table 2 we report the estimates for models parameterized in WTP space.

Results showed statistically significant values for all attributes. The biological information (organic) attribute results showed preference for non-organic products rather than organic products. Furthermore, results showed preferences for producer brands rather than private-labeled ones. Focusing on the flavor attribute preferences, results showed preference for original non-dairy beverage flavor, similar to the results obtained by Siegrist et al. [55], rather than chocolate flavor. Such tendency could be emphasized when deciding on marketing strategies by producing more products in natural flavors without any additional taste. For the additional ingredients attribute, results showed preferences for the dairy-alternative drinks without additional compounds and those with added calcium and vitamins. The selected households showed a negative preference for only added natural calcium. Finally, the last attribute that represented the types of dairy alternatives, we noticed that soy drinks were more preferred than rice and oats drinks.

Consumers who made their purchase of a dairy-alternative drink were willing to pay an extra $0.18 € /$ unit to purchase the producer-branded, an additional $0.89 € /$ unit for original flavor, and only $0.11 € /$ unit for chocolate flavor. They also exhibited a WTP of $0.27 € /$ unit to obtain a dairy alternative without additional ingredients, while they were willing to pay only an additional $0.16 € /$ unit for those added calcium and vitamins. In addition, they were willing to pay an extra $0.56 € /$ unit to make the purchase of soy drinks and an extra $0.23 €$ /unit to obtain the oat drinks. However, they were willing to accept a discount of $1.16 € /$ unit to purchase organic dairy-alternative drinks and $0.17 € /$ unit to purchase a dairy alternative with natural calcium, while they required a discount of $0.19 € /$ unit to purchase a rice-type drink.

\subsection{Factors Affecting the Purchasing Frequency of Dairy Alternatives}

The results of the estimated $P$ and NB models are shown in Table 3. The categorical independent variables allowed us to determine the percentage increase or decrease in counts of one group versus the base level. For continuous independent variables we were able to interpret how a single unit increase or decrease in that variable is associated with a percentage increase or decrease in the counts of the dependent variable.

For every extra euro spent on the shopping basket and on the dairy-alternative drinks, the purchase frequency increased, respectively, by $0.4 \%$ and $2 \%$. For the life cycle, the incidence rate for single-parent households, adult couples without children, couples with children of middle age, couples with young children, and young couples without children, in comparison to the group reference, was, respectively, $0.61,0.69,0.72,0.59$, and 0.48 times the incidence rate, while the results obtained by Ellen et al. [56] showed that living with a partner and number of children were insignificant. The incidence rate for the household within the low and medium GSM class was, respectively, 1.21 and 1.21 times the incidence rate of the reference group (high GSM class). The lower middle social class had an incidence rate of 1.20 times the incidence rate of the reference level (upper and upper middle social class). In regards to the homemaker's age range variable, for consumers with ages between 35 and 49 years and between 50 and 64 years, compared to the reference level (homemaker's age range between 18 and 34 years), the purchase number increased, respectively, by 0.50 and 0.51 times, showing that the older consumers buy the dairy-alternative drinks more frequently, similar to the results obtained by Ellen et al. [56] and in contrast with the results obtained by De Silva et al. [57]. Furthermore, the incidence rate for households within municipal habitats between 30,001 and 100,000 habitants was 0.87 times the incidence rate for the reference group (municipal habitats less than 10,000). Likewise, the 
incidence rate for households within municipal habitats with more than 500,000 habitants was 1.26 times the incidence rate for the reference group holding the other variables at constant.

Table 3. Poisson and negative binomial regressions estimates.

\begin{tabular}{|c|c|c|c|c|c|c|}
\hline \multirow{2}{*}{ Explanatory Variables } & \multicolumn{3}{|c|}{ Poisson } & \multicolumn{3}{|c|}{ Negative Binomial } \\
\hline & Estimates & Std. Error & $\exp ^{\text {Esti. }}$ & Estimates & Std. Error & $\exp ^{\text {Esti. }}$ \\
\hline Expenditure of the shopping basket & $0.003^{* * *}$ & 0.00 & 1.003 & $0.01 * * *$ & 0.00 & 1.004 \\
\hline Independent adults & -0.28 & 0.12 & 0.75 & -0.26 & 0.14 & 0.77 \\
\hline Single-parent households & $-0.51^{* * *}$ & 0.12 & 0.60 & $-0.49^{* * *}$ & 0.13 & 0.61 \\
\hline Young independent households & -0.43 & 0.29 & 0.65 & -0.51 & 0.35 & 0.60 \\
\hline Couples with children of middle age & $-0.40^{* * *}$ & 0.10 & 0.68 & $-0.32 * *$ & 0.12 & 0.72 \\
\hline Couples with older children & $-0.31 * *$ & 0.11 & 0.73 & -0.25 & 0.13 & 0.78 \\
\hline Couples with young children & $-0.65^{* * *}$ & 0.10 & 0.52 & $-0.52^{* * *}$ & 0.12 & 0.59 \\
\hline Young couple without children & $-0.88^{* *}$ & 0.29 & 0.41 & -0.73 & 0.34 & 0.48 \\
\hline Retirees & 0.09 & 0.15 & 1.09 & 0.08 & 0.18 & 1.09 \\
\hline Lower GSM class & $0.20 * * *$ & 0.06 & 1.22 & $0.19 * *$ & 0.07 & 1.21 \\
\hline Homemaker's age range between 35 and 49 & $0.33^{* * *}$ & 0.09 & 1.39 & $0.40^{* * *}$ & 0.11 & 1.50 \\
\hline Homemaker's age range between 50 and 64 & $0.32 * *$ & 0.11 & 1.38 & $0.41^{* *}$ & 0.13 & 1.51 \\
\hline Homemaker's age range more than 65 & -0.02 & 0.15 & 0.98 & 0.11 & 0.17 & 1.11 \\
\hline Residence in municipal habitat $(10,001-30,000)$ & -0.06 & 0.06 & 0.94 & -0.05 & 0.07 & 0.95 \\
\hline Residence in municipal habitat $(100,001-500,000)$ & -0.06 & 0.06 & 0.95 & -0.04 & 0.07 & 0.96 \\
\hline Residence in municipal habitat $(30,001-100,000)$ & $-0.22 * * *$ & 0.06 & 0.80 & -0.14 & 0.07 & 0.87 \\
\hline Residence in municipal habitat $(>500,000)$ & $0.17^{* * *}$ & 0.05 & 1.18 & $0.24^{* * *}$ & 0.06 & 1.26 \\
\hline Number of visited purchase places & $0.79^{* * *}$ & 0.02 & 2.20 & $1.04^{* * *}$ & 0.02 & 2.73 \\
\hline
\end{tabular}

*** $1 \%$ and ${ }^{* *} 5 \%$ significance level.

\subsection{Consumers' Heterogeneity Analysis}

We identified the consumers' heterogeneity by carrying out a K-means cluster analysis on the aggregated data, using the average values by purchase occasion along the year of both variables, representing the total expenditure of the shopping basket and the expenditure on the dairy-alternative drinks. Table 4 presents the results of an ANOVA test for the results of K-means cluster analysis that produced a solution in three clusters. The target variables were two factors that represent consumers' expenditure.

Table 4. ANOVA table for three-cluster solution.

\begin{tabular}{ccc} 
Clustering Variables & F & Sig. \\
\hline The average of the expenditure of the shopping basket $(€)$ & 858.40 & 0.000 \\
The average of the expenditure on the alternative dairy drinks per basket $(€)$ & 10.15 & 0.000 \\
\hline
\end{tabular}

Assuming a significance level of 5\% (0.050) the significance statistic (Sig.) indicates that the null hypothesis was rejected for the average of the expenditure of the shopping basket $(\mathrm{F}=858.40$, Sig. $=0.000)$, and for the average of the expenditure on the dairy-alternative drinks per basket $(\mathrm{F}=10.15$, Sig. $=0.000)$. Hence, the results of the test confirmed that the clusters were different. From Table 5 and based on both average expenditure on the dairy-alternative drinks and average shopping basket value, the consumers of the third cluster spent more money on both variables, followed by the first cluster and the second one. 
Table 5. Final cluster centers.

\begin{tabular}{cccc}
\hline Clusters' Mean and Sample Distribution & \multicolumn{3}{c}{ Cluster } \\
\cline { 2 - 4 } Percentage of the sample & $\mathbf{1}$ & $\mathbf{2}$ & $\mathbf{3}$ \\
\hline The average of the expenditure of the shopping basket $(€)$ & $28 \%$ & $62 \%$ & $10 \%$ \\
The average of the expenditure on the dairy-alternative drinks per basket $(€)$ & 4.7 & 25.8 & 131.5 \\
\hline
\end{tabular}

As shown in the Table 5, the households involved in the study were unequally distributed among the three clusters, where $62 \%$ of the sample belonged to the second cluster, around $28 \%$ to the first, and the remaining $10 \%$ to the third one. Further, the segments were described. First, a test of ANOVA was performed in order to check the differences between the three clusters using the cluster membership variable and a post hoc analysis, more specifically the Games-Howell and Tukey tests. The significance of the statistic indicated that the null hypothesis was rejected at $5 \%$ of significance level for "the number of purchases" and "the number of purchased units by purchase occasion" and accepted for the variable "expenditure by unit". Therefore, the results of the tests confirmed that there was a heterogeneity of variances for the variables "the number of purchases" and "the number of purchased units by purchase occasion" and for the variable "expenditure by unit" there was homogeneity of variance.

Then, for the first two variables we applied robust tests of equality of means, the results of the Welch and Brown-Forsythe tests showed that both tests were significant at $5 \%$ significance level for the variables "the number of purchases" and "the number of purchased units by purchase occasion", hence there was a statistically significant difference between the clusters on account of these two variables. For the "expenditure by unit" variable, results showed non-significance for the two tests and thus a non-significant difference between the clusters.

As can be seen in Table 6, results showed that for "the number of purchases" variable the members of the first cluster did not show significant results, while the members belonging to the other two clusters showed significant results. This indicates that the individuals in the second cluster made more purchases than the individuals in the third cluster, while the individuals in the first clusters did not differ from the other two clusters. Concerning "the number of purchased units by purchase occasion" variable, the Tukey test (Table 6) showed a non-difference between clusters 1 and 3 and a difference between these two clusters and cluster 2 . In other words, the individuals in clusters 1 and 3 bought more units than the individuals in cluster 2.

Table 6. Games-Howell and Tukey tests.

\begin{tabular}{ccccc}
\hline Purchasing Behavior Variables & Test & Cluster 1 & Cluster 2 & Cluster 3 \\
\hline \multirow{2}{*}{ Number of purchases } & Games-Howell & $9.30^{\mathrm{a}, \mathrm{b}}$ & $12.45^{\mathrm{a}}$ & $6.50^{\mathrm{b}}$ \\
& Tukey & $9.30^{\mathrm{a}, \mathrm{b}}$ & $12.45^{\mathrm{a}}$ & $6.50^{\mathrm{b}}$ \\
\hline Number of purchased units by & Games-Howell & $4.73^{\mathrm{a}}$ & $2.90^{\mathrm{b}}$ & $5.81^{\mathrm{a}, \mathrm{b}}$ \\
purchase occasion & Tukey & $4.73^{\mathrm{a}}$ & $2.90^{\mathrm{b}}$ & $5.81^{\mathrm{a}}$ \\
\hline
\end{tabular}

${ }^{a}$ : Significant at $95 \%$; : Significant at $95 \%$; ${ }^{\text {a,b }}$ : Significant at $95 \%$.

Second, a Chi-square test was applied to sociodemographic characteristics. Results showed that the variables life cycle, social class, and homemaker's age range had statistically significant results at $5 \%$ significance level, which allowed us to reject the null hypothesis of independence between the correspondent variables and the cluster membership variable. After the test, a cross-tabulation between the sociodemographic variables one-by-one and the cluster membership variables was carried out to describe the three clusters.

As shown in the Table 7, the first cluster was characterized by the biggest percentage of couples with young children among the three clusters; the second cluster was characterized by the biggest 
percentage of adult couples without children and retirees; while the third involved more couples with median aged children and with older children.

Table 7. Crosstab for cluster membership and life cycle variable.

\begin{tabular}{cccc}
\hline Life Cycle & $\begin{array}{c}\text { Cluster 1 } \\
\text { Average } \\
\text { Expenditure }\end{array}$ & $\begin{array}{c}\text { Cluster 2 } \\
\text { Low } \\
\text { Expenditure }\end{array}$ & $\begin{array}{c}\text { Cluster 3 } \\
\text { High } \\
\text { Expenditure }\end{array}$ \\
\hline Independent adults & $3.2 \%$ & $9.8 \%$ & $5.9 \%$ \\
Single parents & $8.4 \%$ & $9.8 \%$ & $0.0 \%$ \\
Independent youth & $2.1 \%$ & $3.7 \%$ & $0.0 \%$ \\
Adult couple without children & $9.5 \%$ & $19.2 \%$ & $17.6 \%$ \\
Couples with median aged children & $23.2 \%$ & $12.6 \%$ & $23.5 \%$ \\
Couples with older children & $16.8 \%$ & $11.2 \%$ & $20.6 \%$ \\
Couples with young children & $21.1 \%$ & $14.5 \%$ & $17.6 \%$ \\
Young couples without children & $8.4 \%$ & $5.1 \%$ & $11.8 \%$ \\
Retirees & $7.4 \%$ & $14.0 \%$ & $2.9 \%$ \\
Total & $100.0 \%$ & $100.0 \%$ & $100.0 \%$ \\
\hline
\end{tabular}

Table 8 shows that the biggest percentage within each of the three clusters belonged to the middle class, while the second cluster was the one with the highest percentage of lower middle class and lower class, and the third cluster had a high proportion of individuals from the upper and upper middle class.

Table 8. Crosstab for cluster membership and Social Class variable.

\begin{tabular}{cccc}
\hline Social Class & Cluster 1 & Cluster 2 & Cluster 3 \\
\hline Upper and upper middle class & $26.3 \%$ & $20.1 \%$ & $32.4 \%$ \\
Middle class & $41.1 \%$ & $36.0 \%$ & $55.9 \%$ \\
Lower middle class & $22.1 \%$ & $25.2 \%$ & $5.9 \%$ \\
Lower class & $10.5 \%$ & $18.7 \%$ & $5.9 \%$ \\
Total & $100.0 \%$ & $100.0 \%$ & $100.0 \%$ \\
\hline
\end{tabular}

Concerning the homemaker's age range variable, the results in the Table 9 show that more than half of the individuals in the first cluster had an age between 35 and 49 years, while the second cluster included a higher percentage of the persons aged between 50 and 64 years old, and included a relatively high number of aged individuals. The third cluster included more young individuals than the other two clusters.

Table 9. Crosstab for cluster membership and age of homemaker variable.

\begin{tabular}{cccc}
\hline Age of Homemaker & Cluster 1 & Cluster 2 & Cluster 3 \\
\hline From 18 to 35 & $9.5 \%$ & $5.1 \%$ & $26.5 \%$ \\
From 35 to 49 & $53.7 \%$ & $36.9 \%$ & $23.5 \%$ \\
From 50 to 64 & $29.5 \%$ & $41.6 \%$ & $35.3 \%$ \\
More than 64 & $7.4 \%$ & $16.4 \%$ & $14.7 \%$ \\
Total & $100.0 \%$ & $100.0 \%$ & $100.0 \%$ \\
\hline
\end{tabular}

As a conclusion for all above-mentioned variables, we could conclude that the second cluster's members spent less money on the dairy-alternative drinks and on food in general, while they made a higher number of purchases but they bought less number of units per purchase occasion. They belonged to the lower middle class and lower class, were generally adult couples without children, and retirees with an average homemaker's age over 50 years.

In contrast, the third cluster members spent more money, devoted a higher budget for the dairy-alternative drinks and for the food shopping in general, they made less numbers of purchases 
but they bought a higher number of units per purchase than the second cluster. They belonged to the middle class and the higher and higher middle classes, mostly couples with median aged children and couples with older children, with generally a younger homemaker.

The first cluster was a mixture of individuals with medial sociodemographic characteristics and expenditure on the dairy-alternative drinks and on food. They were mainly middle class households, couples with young children, and a homemaker's age between 35 and 49 years.

\section{Conclusions}

As expected, results showed negative signs on the marginal utility of the price, indicating that an increase in the price will decrease the utility of the dairy-alternative drinks offered to consumers. Such a result emphasizes that the price attribute is a relevant driving factor for producing dairy-alternative drinks as consumers are sensitive to price and may change their attributes towards dairy alternative drinks if they notice an increase in the price.

Another important attribute was the flavor. The original non-dairy beverage flavor compared to the other flavors showed higher contribution to consumers' utility when making the purchase of dairy-alternative drinks. Such an indicator could be emphasized when deciding on marketing strategies in a way to make it profitable, by producing more products in natural flavors without any additional taste. Marketing strategies should promote products by focusing on the "original" and "pure" version of the product without additional healthy ingredients and with reduction of the undesirable compounds they existed.

In addition, consumers prefer manufacturer brands against the private ones, which is an indicator to industry of the higher contribution of their own brands to consumers' utility as an added value when making the purchase decision. Concerning the remaining attributes, results showed that consumers do not take into account the organic production alternative during the purchase occasion, which means that this doesn't present a profitable tool in marketing strategies, and they exhibited a preference for soy drinks without additional ingredients.

Concerning the factor affecting the purchase frequency of the dairy-alternative products, results showed that for every extra euro spent on the shopping basket and on the dairy-alternative drinks, the purchase frequency increased, respectively, by $0.4 \%$ and $2 \%$. The purchase frequency increased significantly with age, highlighting the relevance of marketing strategies that focus on older consumers for the purchase of dairy-alternative drinks with more frequent purchase behavior.

Finally, these results are tightly related to the aggregation decision made for the different products with very low purchase frequency that could have led to information lost. Alternative aggregation procedures and modeling approaches can be further applied to test for the validity of our results.

Author Contributions: Conceptualization, M.L. and Z.K.; methodology, Z.K. and M.L.; software, M.L. and Z.K.; validation, Z.K.; formal analysis, M.L. and Z.K.; investigation, M.L. and Z.K.; data curation, M.L.; writing-original draft preparation, M.L.; writing-review and editing, Z.K.; supervision, Z.K.; project administration, Z.K.

Funding: This research received no external funding.

Conflicts of Interest: The authors declare no conflict of interest.

\section{References}

1. Ugidos-Rodríguez, S.; Matallana-González, M.C.; Sánchez-Mata, M.C. Lactose malabsorption and intolerance: A review. Food Funct. 2018, 9, 4056-4068. [CrossRef] [PubMed]

2. Woodside, J.V.; Brennan, S.; Cantwell, M. Are Soy-Milk Products Viable Alternatives to Cow's Milk? In Beverage Impacts on Health and Nutrition; Springer International Publishing: Berlin/Heidelberg, Germany, 2016; pp. 151-162.

3. Rangel, A.; Sales, D.; Urbano, S.; Galvao, J.; Andrade, J.; Macedo, C. Lactose intolerance and cow's milk protein allergy. Food Sci. Technol. 2016, 32. [CrossRef]

4. Europe Dairy Alternative Market. Available online: http://www.micromarketmonitor.com/market/europedairy-alternative-2585396357.html (accessed on 18 October 2018). 
5. Jayne, V.W.; Michael, S.M. Are Soy-Milk Products Viable Alternatives to Cow's Milk? In Beverages in Nutrition and Health; Wilson, T., Temple, N.J., Eds.; Humana Press Inc.: Totowa, NJ, USA, 2004.

6. Mäkinen, O.E.; Wanhalinna, V.; Zannini, E.; Arendt, E.K. Foods for special dietary needs: Non-dairy plant-based milk substitutes and fermented dairy-type products. Crit. Rev. Food Sci. Nutr. 2016, 56, 339-349. [CrossRef] [PubMed]

7. Jago, D. Free from Foods-Mintel report. In FreeFrom Allergy and Intolerance 2011; FDIN Seminar: Daventry, UK, 2011.

8. Leatherhead Food Research. Food Allergies and Intolerances: Consumer Perceptions and Market Opportunities for 'Free From' Foods; Leatherhead Food International: Surrey, UK, 2010.

9. Oltenacu, P.A.; Broom, D.M. The impact of genetic selection for increased milk yield on the welfare of dairy cows. Anim. Welf. 2010, 19, 39-49.

10. Broom, D.M. The use of the concept Animal Welfare in European conventions, regulations and directives. Food Chain 2001, 2001, 148-151.

11. McGlone, J. Farm animal welfare in the context of other societal issues: Toward sustainable systems. Livest. Prod. Sci. 2001, 72, 75-81. [CrossRef]

12. Loomis, J.B. Strategies for overcoming hypothetical bias in stated preference surveys. J. Agric. Resour. Econ. 2014, 39, 34-46.

13. Lusk, J.L.; Schroeder, T.C. Are choice experiments incentive compatible? A test with quality differentiated beef steaks. Am. J. Agric. Econ. 2004, 86, 467-482. [CrossRef]

14. Chang, J.B.; Lusk, J.L.; Norwood, F.B. How closely do hypothetical surveys and laboratory experiments predict field behavior? Am. J. Agric. Econ. 2009, 91, 518-534. [CrossRef]

15. Robert, C.F.; Matthew, M.S. Introduction to: Scanner Data and Price Indexes; University of Chicago Press: Chicago, IL, USA, 2003.

16. Nayga, R.M., Jr. Scanner Data in Supermarkets: Untapped Data Source for Agricultural Economists; Review of Marketing and Agricultural Economics; Australian Agricultural and Resource Economics Society: Melbourne, Australia, 1992; Volume 60, pp. 1-8.

17. Adamowicz, W.; Louviere, J.; Williams, M. Combining revealed and stated preference methods for valuing environmental amenities. J. Environ. Econ. Manag. 1994, 26, 271-292. [CrossRef]

18. Swait, J.; Andrews, R.L. Enriching scanner panel models with choice experiments. Mark. Sci. 2003, 22, 442-460. [CrossRef]

19. Whitehead, J.C.; Pattanayak, S.K.; Van Houtven, G.L.; Gelso, B.R. Combining revealed and stated preference data to estimate the nonmarket value of ecological services: An assessment of the state of the science. J. Econ. Surv. 2008, 22, 872-908. [CrossRef]

20. Brooks, K.; Lusk, J.L. Stated and revealed preferences for organic and cloned milk: Combining choice experiment and scanner data. Am. J. Agric. Econ. 2010, 92, 1229-1241. [CrossRef]

21. Helveston, J.P.; Feit, E.M.; Michalek, J.J. Pooling stated and revealed preference data in the presence of RP endogeneity. Transp. Res. Part B Methodol. 2018, 109, 70-89. [CrossRef]

22. Ward, M.B.; Shimshack, J.P.; Perloff, J.M.; Harris, J.M. Effects of the private-label invasion in food industries. Am. J. Agric. Econ. 2002, 84, 961-973. [CrossRef]

23. Vickner, S.S.; Davies, S.P. Estimating strategic price response using cointegration analysis: The case of the domestic black and herbal tea industries. Agribus. Int. J. 2002, 18, 131-144. [CrossRef]

24. Cotterill, R.W.; Franklin, A.W. An estimation of consumer benefits from the public campaign to lower cereal prices. Agribus. Int. J. 1999, 15, 273-287. [CrossRef]

25. Bonnet, C.; Simioni, M. Assessing consumer response to protected designation of origin labeling: A mixed multinomial logit approach. Eur. Rev. Agric. Econ. 2001, 28, 433-449. [CrossRef]

26. Chevalier, J.A.; Kashyap, A.K.; Rossi, P.E. Why don't prices rise during periods of peak demand? Evidence from scanner data. Am. Econ. Rev. 2004, 93, 15-37. [CrossRef]

27. Mathios, A.D. The importance of nutrition labeling and health claim regulations on product choice: An analysis of the cooking oil market. Agric. Resour. Econ. Rev. 1998, 27, 159-168. [CrossRef]

28. Guadagni, P.M.; Little, J.D.C. A Logit Model of Brand Choice Calibrated on Scanner Data. Mark. Sci. 1983, 2, 203-238. [CrossRef] 
29. Pancras, J.; Dey, D.K. A comparison of generalized multinomial logit and latent class approaches to studying consumer heterogeneity with some extensions of the generalized multinomial logit model. Appl. Stoch. Models Bus. Ind. 2011, 27, 567-578. [CrossRef]

30. Wasi, N.; Keane, M. Estimation of Discrete Choice Models with Many Alternatives Using Random Subsets of the Full Choice Set: With an Application to Demand for Frozen Pizza; No. 2012-W13; Economics Group, Nuffield College, University of Oxford: Oxford, UK, 2010.

31. Hury, J.; Lamboray, C. The Use of Scanner Data in the Luxembourg CPI: First Lessons Learned; Institut national de la statistique et des études économiques du Grand-Duché de Luxembourg: Luxembourg, 2013.

32. Cohen, M.A.; Rysman, M. Payment Choice with Consumer Panel Data; Federal Reserve, Bank of Boston: Boston, MA, USA, 2013.

33. Einav, L.; Leibtag, E.; Nevo, A. On the Accuracy of Nielsen Homescan Data; ERR-69-56490; United States Department of Agriculture, Economic Research Service: Washington, DC, USA, 2008.

34. Hardesty, D.M.; Goodstein, R.C.; Grewal, D.; Miyazaki, A.D.; Kopalle, P. The accuracy of scanned prices. J. Retail. 2014, 90, 291-300. [CrossRef]

35. Lusk, J.L.; Brooks, K. Who participates in household scanning panels? Am. J. Agric. Econ. 2011, 93, $226-240$. [CrossRef]

36. Gidlöf, K.; Anikin, A.; Lingonblad, M.; Wallin, A. Looking is buying. How visual attention and choice are affected by consumer preferences and properties of the supermarket shelf. Appetite 2017, 116, 29-38. [CrossRef] [PubMed]

37. Lancaster, K. A new approach to consumer theory. J. Political Econ. 1966, 74, 132-157. [CrossRef]

38. Train, K.E. Discrete Choice Methods with Simulation; Cambridge University Press: Cambridge, UK, 2003.

39. McFadden, D. Conditional logit analysis of qualitative choice behavior. In Frontiers in Econometrics; Zarembka, P., Ed.; Academic Press: New York, NY, USA, 1974.

40. McFadden, D.; Train, K. Mixed MNL models for discrete response. J. Appl. Econ. 2000, 15, 447-470. [CrossRef]

41. Train, K. Discrete Choice Methods with Simulation, 2nd ed.; University Press: Cambridge, UK, 2009; ISBN 0-521-74738-4.

42. Ben-Akiva, M.; McFadden, D.; Abe, M.; Bockenholt, U.; Bolduc, D.; Gopinath, D.; Morikawa, T.; Ramaswamy, V.; Rao, V.; Revelt, D.; et al. Modeling Methods for Discrete Choice Analysis. Mark. Lett. 1997, 8, 273-286. [CrossRef]

43. Fiebig, D.G.; Keane, M.P.; Louviere, J.; Wasi, N. The generalized multinomial logit model: Accounting for scale and coefficient heterogeneity. Mark. Sci. 2010, 29, 393-421. [CrossRef]

44. Hole, A.R.; Kolstad, J.R. Mixed logit estimation of willingness to pay distributions: A comparison of models in preference and WTP space using data from a health-related choice experiment. Empir. Econ. 2012, 42, 445-469. [CrossRef]

45. Train, K.; Weeks, M. Discrete choice models in preference space and willingness-to-pay space. In Applications of Simulation Methods in Environmental and Resource Economics; Alberini, A., Scarpa, R., Eds.; Kluwer Academic Publishers: Boston, MA, USA; Dordrecht, The Netherlands; London, UK, 2005; pp. 1-16.

46. Muñiz, C.; Rodríguez, P.; Suárez, M.J. Sports and cultural habits by gender: An application using count data models. Econ. Model. 2014, 36, 288-297. [CrossRef]

47. Cameron, A.C.; Trivedi, P.K. Regression Analysis of Count Data; Cambridge University Press: Cambridge, UK, 2013; Volume 53.

48. Lichung, J.; Chou, C.H.; Greg, M.A. A Bayesian Approach to Modeling Purchase Frequency. Mark. Lett. 2003, 14, 5-20.

49. Cox, D.R. Some remarks on over-dispersion. Biometrika 1983, 70, 269-274. [CrossRef]

50. Econometric Modeling Guide, LIMDEP Version 10; Econometric Software, Inc. Available online: http://people.stern.nyu.edu/wgreene/Lugano2013/A\%20Quickstart\%20Introduction\%20to\%20NLOGIT\% 20and\%20LIMDEP.pdf (accessed on 24 April 2019).

51. Hensher, D.A.; Rose, J.M.; Greene, W.H. Applied Choice Analysis: A Primer; Cambridge University Press: Cambridge, UK, 2005; pp. 338-339.

52. R Core Team. R: A Language and Environment for Statistical Computing; R Foundation for Statistical Computing: Vienna, Austria, 2018.

53. Idescat. Instituto de Estadística de Cataluña. 2018. Available online: $w w w \cdot i d e s c a t . c a t / p u b / ? i d=a e c \& n=245 \&$ lang=en (accessed on 24 April 2019). 
54. De-Magistris, T.; Gracia, A.; Nayga, R.M., Jr. On the use of honesty priming tasks to mitigate hypothetical bias in choice experiments. Am. J. Agric. Econ. 2013, 95, 1136-1154. [CrossRef]

55. Siegrist, M.; Stampfli, N.; Kastenholz, H. Acceptance of nanotechnology foods: A conjoint study examining consumers' willingness to buy. Br. Food J. 2009, 111, 660-668. [CrossRef]

56. Van Loo, E.; Caputo, V.; Nayga, R.M., Jr.; Meullenet, J.-F.; Crandall, P.G.; Ricke, S.C.; Nayga, J. Effect of Organic Poultry Purchase Frequency on Consumer Attitudes Toward Organic Poultry Meat. J. Food Sci. 2010, 75, S379-S384. [CrossRef] [PubMed]

57. De Silva, P.; Atapattu, N.; Sandika, A. A study of the socio-cultural parameters associated with meat purchasing and consumption pattern: A case of Southern Province, Sri Lanka. J. Agric. Sci. 2011, 5, 71-79. [CrossRef]

(C) 2019 by the authors. Licensee MDPI, Basel, Switzerland. This article is an open access article distributed under the terms and conditions of the Creative Commons Attribution (CC BY) license (http://creativecommons.org/licenses/by/4.0/). 